\title{
Consumer effects of environmental impact in product labeling
}

Norm Borin and Douglas C. Cerf

\author{
R. Krishnan
}

\begin{abstract}
Purpose - The purpose of this paper is to investigate the impact of different levels of environmental information on key consumer metrics. More specifically, it aims to evaluate environmentally benign products against those that have negative environmental impacts.

Design/methodology/approach - Multiple product categories and messages that varied from strongly negative to strongly positive were used to test whether the accuracy/completeness of the information changes consumers' view of green products.

Findings - The results show that consumer perception of product quality, value, and purchase intentions does not differ significantly between products with positive environmental messages and those without any message. Products with positive environmental messages are viewed better than products with negative environmental messages. It is also found that the impact of environmental information is greater for consumable products. Practical implications - Clearly presented information can make a significant difference in consumer evaluation of products. If green products highlighted the reasons why products free of harmful ingredients did not have a negative impact on the environment, and if non-green products were required to disclose the harmful impact of their ingredients, green products would be favorably perceived over the non-green alternative.

Social implications - The paper conjectures that if "fair" and clear explanations of environmental impact, both good and bad, are required, consumer evaluations of green products will improve and, ultimately, a larger percentage of consumers will purchase green products. The findings suggest that policy makers should require manufacturers to disclose key product ingredients and their environmental impact.

Originality/value - This project adds to the growing body of literature on environmental labeling, and investigates the effects of different levels of environmental information on key consumer metrics.
\end{abstract}

Keywords Environmental management, Labelling, Information disclosure, Packaging, Green marketing

An executive summary for managers and executive readers can be found at the end of this article.

\section{Introduction}

Today's marketplace is increasingly attractive for marketers of green products. Consumers are expected to double their spending on "green" products, reaching $\$ 500$ billion in 2009 (CBS News, 2008), and many consumers state that they are willing to pay a price premium for these products (Veisten, 2007; Vlosky et al., 1999; Wüstenhagen, 1998). Recent studies indicate that 93 percent of consumers say they participate in efforts to sustain environment (Hartmann Group, 2007), and a large segment, 37 percent, feel highly concerned about the environment (California Green Solutions, 2007). Companies have responded to this data with increased development and release of sustainable products. The number of self-labeled "green" products released in the USA more than doubled between 2005 and 2007, from 2607 to 5933 (Wasserman, 2009).
Despite these positive trends, recent research with green products show cause for concern and foretell a potential limit to the growth in the industry. Studies have found that consumers believe that green products are priced higher and of poorer quality than the non-green alternative (D'Souza et al., 2007). Other authors have determined that green communication is the major area of weakness. Pickett-Baker and Ozaki (2008) found that, except for cleaning products, most consumers cannot identify greener products. This may be because most green messages labels are falling flat and not making an impression in the minds of shoppers (Green Biz Staff, 2009). In a survey of more than 2000 consumers most of the more than 400 green labels currently used on products failed to have any consumer recognition with only two, Energy Star and the widespread recycling arrows, changing consumer behaviors.

Consumers have indicated a lack of trust and growing confusion over the plethora of government, corporate and third-party eco-symbols on a wide variety of products (Bhaskaran et al., 2006; Terrachoice Environmental Marketing, 2009). Adding to the confusion are the increasing numbers of companies developing their own proprietary labels in order to differentiate themselves in the marketplace. There is a growing call for clearer communication about the consumer benefits of green products (Pickett-Baker and Ozaki, 2008). The recent State of Green Business Forum (2010) reported that green information needed to be "accessible in an easily understandable manner right at the point of purchase" (Mazur, 2010). 
This project adds to the growing body of literature on environmental labeling, and investigates the effects of different levels of environmental information on key consumer metrics. Misleading, or in some cases incorrect, environmental claims by some companies can negatively impact sales of companies with legitimate green claims, and can increase consumer skepticism towards green product claims in general. How can consumers assess the environmental effects of the products? If the information were clearly presented, would consumers be more likely to view the quality of green products more positively? Currently, companies are not required to disclose all product ingredients or the environmental impact of these ingredients. Even recognizable symbols can have different meanings. For example, the three-chasing-arrows recycling symbol can be used to represent a product that is made out of recycled material or one that is recyclable. Claims such as environmentally safe or packages with an earth and flower on it do not provide consumers with specific information to make an informed decision regarding the environmental impact of the product.

Of particular interest in this research is our comparison of environmentally benign products with products that are not required to disclose their possible negative environmental effects. Green products are those that do not harm the environment and contain no potentially harmful elements. Although some green products provide substantive information on what makes them green, this is not the norm. Just as important, products that make no claim to be green are not required to provide information on their environmental impact. A product might fully disclose what makes it environmentally friendly, but may still have factors that create negative impact.

For example, food products grown with pesticides are not required to state this information, or to present the harmful effects of pesticides. We conjecture that if "fair" and clear explanations of environmental impact, both good and bad, are required, consumer evaluations of green products will improve and, ultimately, a larger percentage of consumers will purchase green products.

\section{Environmental labeling research and hypotheses}

In this paper we use the terminology "eco-labeling" and "environmental labeling" as synonymous descriptors that refer to information a product provides "about the environmental impacts associated with the production or use of a product" (Rotherham, 1999). Research in the area of eco-labeling is currently at a stage similar to that of nutritional labeling two decades ago, which provided significant insight into the types of people who use nutritional labels, the desired format and detail of information, and the impacts of labels on dietary changes and purchase behavior. This type of research is just beginning in eco-labeling, but will likely continue as key stakeholders explore the numerous possibilities for communicating accurate information in a cost-efficient and effective manner.

\section{Effect of environmental information on consumer judgment}

Environmental information on products can be presented on a continuum that ranges from simple symbols, to color codes to other labels with basic information and to detailed environmental information about single or multiple product ingredients. Most consumer products that provide environmental information focus on symbols or logos that attempt to convey an array of environmental information. Unfortunately, consumers must decipher the meanings of these labels, and research indicates that consumers often have difficulty understanding what the labels intend to communicate (Thøgersen, 2000). Terms such as "recyclable", "eco-friendly", "environmentally safe" are vague and may create cynicism among consumers. The large number of symbols/labels adds to consumer difficulty in assessing the comparable advantages of different products. Some labels are also incomplete in terms of proving full environmental disclosure. For example, the Energy Star label on washing machines provides information on energy usage but does not include information on water usage, which is another area of critical environmental impact.

In contrast with prior research that used symbols or general statements, our research investigates the effects of specific environmental label information on consumer perceptions of quality, value and purchase intentions. Although supermarkets stock a wide variety of green products, it is surprising how many products do not clearly communicate their reduced environmental impact. Given the lack of clear information about positive environmental impact, and the lack of information about negative impact on the environment that results from limited disclosure regulations, consumers are unable to effectively determine the comparative advantage of an eco-friendly product against a similar product that is not eco-friendly. In order to investigate the effects of impact enclosure, we investigate different levels of environmental information provided on product labels.

Past research has found that consumers react more favorably to positive attribute messages, relative to negative attribute messages (Beach et al., 1996; Buda and Zhang, 2000; Johnson, 1987; Levin and Gaeth, 1988) explain these findings as part of a consumer-encoding process in which positive messages evoke favorable memories, while negative messages evoke less desirable associations. Another explanation is the concept of priming in which the message primes the subject either positively or negatively and this evaluation is transferred to the object (Levin et al., 1998):

$H 1 A$. Positive environmental information will have a positive impact on consumer metrics relative to those products with negative environmental information.

A review of research findings indicates that the negative label has a greater impact on consumers with an intermediate interest in environmental issues than does the positive label. This reflects consumers' sensitivity to keeping things from getting worse, relative to making things better. These findings are consistent with research on nutritional labeling that demonstrated that consumers often use nutrient information to avoid negative nutrients (Abbott, 1997; Hawkes, 2004).

Research on psychological choices by Tversky and Kahneman (1981) and Kahneman and Tversky (1979) has shown that people tend to be more sensitive to losses than to gains (loss aversion principle). This stream of research argues that individuals have a strong aversion to losses, and have a greater response to negative messages than to positive messages (see Levin et al. (1998) for an excellent summary. Levin et al. (1998) suggest that losses have a greater impact on motivation, and thus negative messages will have a greater impact than positive messages. Two potential explanations for this effect are the possibility that negative messages attract more attention or are less common than positive messages 
(Buda and Zhang, 2000) and thus may receive greater attention (Smith and Petty, 1996). Other authors have made the case that consumers will respond more favorably toward products with no negative attributes (Balasubramanian and Cole, 2002)

$H 1 B$. Products with negative environmental messages will have a negative impact on key consumer metrics relative to products with no (neutral) environmental information.

H1C. Negative environmental information will have a greater impact on key consumer metrics than will positive environmental information.

Quality, price, and eco-friendly products

Our second hypothesis represents the status quo for most product categories. Green products, to varying degrees, promote their positive (or less negative) environmental impact while other products fail to disclose their negative environmental impacts (neutral label). The relative consumer evaluation is unclear. Research shows that consumers continue to have guarded impressions of the quality of environmental products (Esty and Winston, 2006; D'Souza et al., 2007), often believing that in order for a product to be green there must be a trade-off on quality. At a minimum the price premium of these products may negatively affect consumer value judgment. Thus, in a situation where, $v i s-\grave{a}-v i s$ a neutral product, the negative perceived quality and price perceptions of green products may negate the benefits of a positive green-safe message we have the following hypothesis:

H2. There will be no significant differences on key consumer metrics between products with positive environmental information and those with no (neutral) environmental information.

More versus less information

Information-processing theories suggest that there is a limit to the amount of information humans can absorb during a specific time period. Jacoby et al. (1974) report that when consumers have more information, satisfaction increases, but decision-making abilities decrease. Heimbach and Stokes (1982) also found that more information is not always better and that consumers prefer information that directly concerns their health. However, in the business-to-business (B2B) environment there seems to be a belief that use of general environmental label together with more specific information is better than simply having specific information (Grankvist and Biel, 2006). This may indicate that consumers prefer more information to less. Abbott (1997) found somewhat conflicting information in the UK. Although more than half of consumers wanted more detailed information, a large number wanted labels that used simpler words. Golan (2000) found "type of information" to be relevant, and Drichoutis et al. (2006) suggest that consumers might be unwilling to evaluate more complicated information. Given the many conflicting findings, we conjecture:

H3. There will be no significant differences on key consumer metrics between environmental messages that provide more or less detail on the impacts of the ingredients.
Nature of consumption and environmental message on product judgment

Heimbach and Stokes (1982) report that consumers find label information relating to known public health problems was the most useful. Grankvist et al. (2004) discovered that consumers' knowledge of a product's risk factors lowered the actual consumption of these products. In 2006, Grankvist and Biel also found that of the three environmental factors (pesticides, greenhouse gases, and energy usage) pesticides had the greatest influence on product purchase. They conjecture that this response may be due to the perception that ingredients such as pesticides have a negative impact on both the environment and on the consumer's health. This finding may lend support to the hypothesis that product categories that have a personal health impact (e.g., foods) may have stronger effects of negative information than products that do not (e.g., bleached paper products). Witte's (1992) extended parallel process model examines how consumers may react to fear appeals and threats. With respect to products, consumers may be more motivated to avoid those products in which they perceive a threat and feel they can do something to avert that threat:

H4. The effects of environmental disclosure on consumer metrics will be greater for products that contain environmentally harmful ingredients and that may have a more direct health risk for the consumer.

\section{Methodology}

We investigate whether results vary by:

- product category; and

- message (environmental information).

\section{Manipulating nature of consumption: direct versus indirect health effects}

To control for product category effects (Grankvist et al., 2004), we conducted our experiment across different product categories. Each product selected provided the opportunity to focus on an ingredient/process that had a potentially negative impact on the environment. We also selected products that provided a variance in the degree of possible direct health impacts the product might have in conjunction with the presence or absence of an environmentally harmful ingredient/process. The ingredient/process selected for the variable manipulation was based on whether the ingredient/ process may be harmful to the environment, and on the product's press coverage.

Apples grown with and without the use of pesticides were selected to represent a product that could have the highest perceived health impact.

Bar soap, with and without formaldehyde as an ingredient, was used to represent a moderate perceived health impact. Although bar soap is not ingested, it has direct contact with the skin and with the body interior through inhalation and exposure to mucous membranes.

Because of the press coverage of the harmful effects of BHA in plastics, MP3 headphones with and without the use of plasticizers were selected to represent a slight health impact.

Finally, paper made of either recycled or non-recycled materials represented a product that had the least health impact. 


\section{Manipulating environmental information}

The study tested five different levels of eco-label information for each product category. At the extremes, the information highlighted the presence or absence of an active ingredient/ process (e.g., pesticides), followed by a specific description regarding the potential environmental harm of the ingredient/ process. The less extreme scenarios presented the absence/ presence of the key ingredient/process, but did not specify the environmental impact. The study also included a presentation of a neutral position. The Appendix, Table AI provides detail on the five different levels of environmental disclosure that were developed to conduct the study:

1 Very positive. The message presents both the absence of an environmentally harmful ingredient/process and a specific impact of this ingredient/process.

2 Positive. The message states both the environmentallyrelated key ingredient/process and a general impact of this ingredient/process.

3 Neutral. There is no environmentally-related message.

4 Negative. The message lists both the presence of an environmentally harmful ingredient/process and a general impact of this ingredient/process.

5 Very negative. The message lists both the presence of an environmentally harmful ingredient/process and a specific impact of this ingredient/process

\section{Data collection}

\section{Survey}

Using a database provided by a local university, we distributed a web survey to 1,435 adults. Recipients were told they would be entered into a random drawing for a $\$ 50$ gift certificate if they returned a completed survey, and we received 329 completed surveys. The response rate of 23 percent was comparable to other web surveys (Kaplowitz et al., 2004). Each participant was given a description of an identical scenario:

Please put yourself into the role of purchaser of the following products and evaluate the products in that context. Even if you don't typically purchase these products, please provide input. Your honest opinion is valued. Results may be used to guide companies in product development and communication. There are no right or wrong answers.

Using birth date (day and month) of the respondents, the survey directed each person to one of the five different information levels in the Appendix, Table AI. Each respondent had the same level for each of the four product categories. Each product scenario included a brief description of the product and an average local price.

\section{Dependent and classification variables}

For each product, respondents were asked to evaluate the perceived quality, value, and purchase intent, based on a seven-point Likert scale. Options within each question were randomly sorted for each respondent. Three items were used for perceived quality, four for perceived value, and two for purchase intentions. Scales were combined and averaged for each metric. The eight questions measuring the degree of environmental attitude of the survey respondents were adapted from earlier work by Weigel and Weigel (1978) and Laroche et al. (2001). Last, along with a series of classification questions, the survey collected measures on product and ingredient/process familiarity and product usage. Manipulation checks were used to evaluate whether the degree of environmental impact for each of the five message levels was clearly communicated.

\section{Results}

\section{Descriptive statistics}

Table I demonstrates that most of the survey respondents had actively purchased the products in the last six months, with a low of 78 percent purchasing bar soap to a high of 93 percent purchasing apples. Over one-half of the sample owns an MP3 player.

Respondents were also asked to rate their familiarity with each of the ingredients/processes of interest in the study. Of the ingredients/processes, respondents were most familiar with pesticides and recycling. A total of 50 percent were familiar with formaldehyde. Given the large percentage of people who are unfamiliar with plasticizers, we carried out additional analysis to ensure that prior knowledge did not affect the results. Mean levels for people familiar and unfamiliar with plasticizers were compared on the bases of quality, value, and purchase intentions. T-test results showed no significant differences (Quality ${ }_{p=0.975}$, Value $_{p=0.463}$, Purchase intention $_{p=0.173}$ ).

Tables I-III present the minimum, maximum, and mean scores of each of the eight attitude questions. Most people in the survey align themselves with environmental attitudes or behaviors, with the highest mean in support of recycling. Individuals were categorized into groups of either strong or weak environmental attitude, and a $t$-test was done on quality, value, and purchase intentions summed across all product categories. Results showed no significant differences (Quality $_{p=0.615}$, Value V $_{p=0.304}$, Purchase intentions ${ }_{p=0.248}$ ) between these groups.

\section{Manipulation check}

Each respondent was asked two questions designed to evaluate whether the scenarios were communicating the intended level of environmental impact. In the apple scenario, for example, respondents were asked to answer a seven-scale Likert in response to "I feel safe using these apples" and "These apples are safe for the environment." We developed analysis at the individual product level and with all products combined. A one-way analysis of variance (ANOVA) for each of these manipulations indicated that the five message levels were perceived in the direction anticipated; e.g. "Very positive" was perceived as the safest to use and safest for the environment (safe to use $F_{4,324}=75.6 p=0.000$, safe for the environment $\left.F_{4,325}=39.3 p=0.000\right)$.

\section{Hypothesis tests \\ Messages}

Table IV presents the mean scores and one-way ANOVA results for all products combined. The results indicate significant effects for the type and level of environmental message across all three consumer metrics. Mean levels are higher for the positive messages and decrease as the message describes an ingredient/process that is more harmful to the environment.

Post-hoc analysis was performed to evaluate the differences between the five levels of environmental messages. These are presented in Table IV for each of the three metrics. Analysis revealed significant differences for all three metrics (Tukey $p<0.05$ ). Results for all metrics show clear support for $H 1 A$ - products with positive environmental messages are perceived as better quality and value, and are more likely to be purchased, than those products that must disclose the negative environmental impacts of their products. Results 
Table I Descriptive statistics

\begin{tabular}{lrr}
\hline & Percent & No \\
& Yes & \\
Have you purchased the following products in the past six months? & & 5 \\
Apples & 93 & 19 \\
Bar soap & 78 & 3 \\
Printer paper & 84 & 3 \\
Do you currently own an MP3 player? & 52 & 45 \\
\hline
\end{tabular}

Table II Descriptive statistics

\begin{tabular}{lcrr}
\hline & Unfamiliar $^{\text {a }}$ & Neither unfamiliar nor familiar & Familiar $^{-}$ \\
\hline Please rate your degree of familiarity with: & $(\%)$ & $(\%)$ & $(\%)$ \\
Pesticides & 14.4 & 13.5 & 69.9 \\
Formaldehyde & 30.7 & 15.6 & 51.2 \\
Plasticizers & 59.6 & 21.5 & 17.3 \\
Recycling & 6.5 & 3.7 & 87.3
\end{tabular}

Note: ${ }^{a}$ The lower and upper three categories of the seven-point Likert scale were summed for this table; because of non-response, row cells do not total to 100 percent

Table III Descriptive statistics

\begin{tabular}{|c|c|c|}
\hline & Mean $^{a}$ & STD $^{a}$ \\
\hline Prefer to buy eco-friendly products & 5.2 & 1.38 \\
\hline Believe human activities are a major reason for global warming & 5.0 & 1.94 \\
\hline Separate trash into recyclable and non-recyclable piles & 6.4 & 1.40 \\
\hline Willing to pay 10 percent more for eco-friendly products & 5.0 & 1.73 \\
\hline I prefer to buy products from eco-friendly companies & 5.1 & 1.59 \\
\hline Pollution is not personally affecting my life & $5.5^{\mathrm{b}}$ & $1.65^{b}$ \\
\hline Would support a college course on conservation for all college students & 5.0 & 1.95 \\
\hline Believe global warming is primarily a natural occurring phenomenon & $4.7^{\mathrm{b}}$ & $1.90^{\mathrm{b}}$ \\
\hline Notes: ${ }^{\text {a }} 1=$ Strongly disagree, $7=$ Strongly agree; ${ }^{b}$ reversed scale & & \\
\hline
\end{tabular}

Table IV Effects of different levels of environmental messages on consumer metrics - all products combined

\begin{tabular}{|c|c|c|c|c|c|c|}
\hline & \multicolumn{2}{|c|}{ Quality } & \multicolumn{2}{|c|}{ Value } & \multicolumn{2}{|c|}{ Purchase intentions } \\
\hline & $\begin{array}{c}F=14.079 \\
\mathrm{df}=325 \\
p=0.000 \\
\text { Mean }^{\mathrm{a}}\end{array}$ & $\begin{array}{l}\text { Tukey significantly } \\
\text { different from }\end{array}$ & $\begin{array}{c}F=23.89 \\
\mathrm{df}=325 \\
p=0.000 \\
\text { Mean }\end{array}$ & $\begin{array}{l}\text { Tukey significantly } \\
\text { different from }\end{array}$ & $\begin{array}{c}F=26.489 \\
\mathrm{df}=325 \\
p=0.000 \\
\text { Mean }\end{array}$ & $\begin{array}{l}\text { Tukey significantly } \\
\text { different from }\end{array}$ \\
\hline & & Negative & & $\begin{array}{l}\text { Neutral } \\
\text { Negative }\end{array}$ & & $\begin{array}{l}\text { Neutral } \\
\text { Negative }\end{array}$ \\
\hline Very positive & 4.71 & $\begin{array}{l}\text { Very negative } \\
\text { Negative }\end{array}$ & 4.82 & $\begin{array}{l}\text { Very negative } \\
\text { Negative }\end{array}$ & 4.69 & $\begin{array}{l}\text { Very negative } \\
\text { Negative }\end{array}$ \\
\hline Positive & 4.50 & Very negative & 4.51 & $\begin{array}{l}\text { Very negative } \\
\text { Very positive } \\
\text { Negative }\end{array}$ & 4.30 & $\begin{array}{l}\text { Very negative } \\
\text { Very positive }\end{array}$ \\
\hline Neutral & 4.26 & Very negative & 4.18 & $\begin{array}{l}\text { Very negative } \\
\text { Very positive }\end{array}$ & 3.80 & $\begin{array}{l}\text { Very negative } \\
\text { Very positive }\end{array}$ \\
\hline Negative & 3.86 & $\begin{array}{l}\text { Very positive } \\
\text { Positive }\end{array}$ & 3.58 & $\begin{array}{l}\text { Positive } \\
\text { Neutral }\end{array}$ & 3.30 & $\begin{array}{l}\text { Positive } \\
\text { Very negative } \\
\text { Very positive }\end{array}$ \\
\hline & & $\begin{array}{l}\text { Very positive } \\
\text { Positive }\end{array}$ & & $\begin{array}{l}\text { Very positive } \\
\text { Positive }\end{array}$ & & $\begin{array}{l}\text { Positive } \\
\text { Neutral }\end{array}$ \\
\hline $\begin{array}{l}\text { Very negative } \\
\text { Note: }{ }^{a} 1-7 \text { scale }\end{array}$ & 3.44 & Neutral & 3.18 & Neutral & 2.72 & Negative \\
\hline
\end{tabular}


were significantly different at both the general and specific message levels.

Much of the literature also supported the hypothesis that negative messages would lower consumer metrics relative to products that had no environmental impact message. The post-hoc analysis in Table IV supports $H 1 B$. Groups exposed to products with no environmental messages, which represents the majority of products currently on the market, had averages higher than those of negative message groups.

Figure 1 illustrates the differential impact across all message levels for the three consumer metrics. Although, as noted above, the metric values decrease as the messages become more negative, there is greater impact in the movement from neutral to negative than in the movement from neutral to positive. These results support $H 1 C$ and are similar to those found in Grankvist et al. (2004).

The second hypothesis is designed to evaluate the current marketplace condition; i.e., most products that contain environmentally harmful ingredients are not required to disclose the fact (neutral condition). However, products that are safe for the environment suffer from either consumer perceptions about their effectiveness (e.g., green cleaners) or negative reactions to perceived or actual price premiums. As expected, Table IV shows mixed results. Stronger environmental messages were perceived significantly better for two of the metrics. However, the more general message (positive) was not significantly better than the neutral message for any metric. These results are examined more closely in the analysis of specific product categories.

Our final evaluation examined the depth of the environmental message. With the exception of one comparison (negative - vs negative in purchase intentions), the results in Table IV support the hypothesis (H3) - that there would be no differences in consumer metrics based on whether the message contained general or specific environmental information (very positive vs positive, and very negative vs negative).

\section{Products}

The analysis above was repeated for each of the four product categories. Most results were consistent with those discussed above; however they were not as strong for products where the environmental risk did not directly impact the potential user (e.g., paper). $H 4$ conjectured that we would not find stronger results as we moved along a continuum from direct to less personal health effect. Table V presents the results for each of the four product categories and the three consumer metrics.

\section{Figure 1 Consumer metrics by message level}

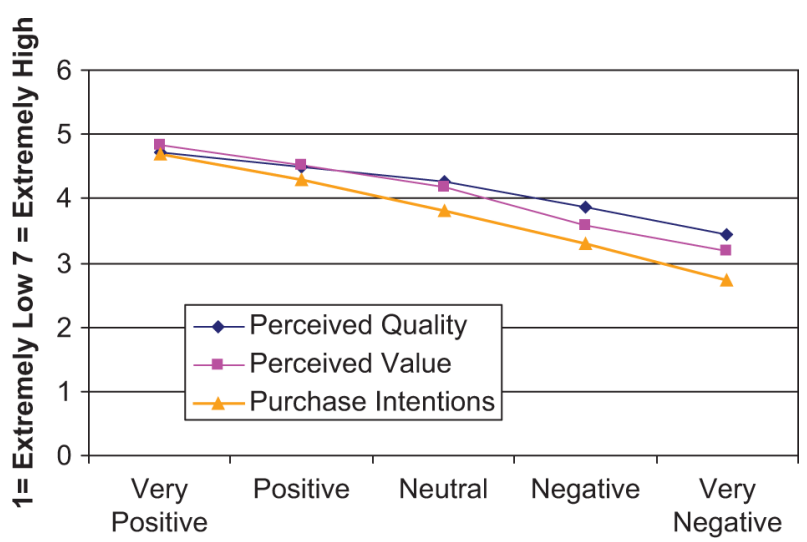

Although we did not find support for the continuum the results clearly show that the differences between the positive and negative messages were significantly smaller for the two products with the least direct health impact, MP3 headphones and paper, than they were for the apples and bar soap. In fact, there were very little differences between positive and negative messages for the headphones and paper. We expand upon this in the discussion section.

\section{Managerial implications and applications}

A recent Wall Street fournal article entitled "As eco-seals proliferate, so do doubts" describes "the increasing confusion among consumers about the veracity of green marketing promises" (Bounds, 2009). The large number of symbols currently used, new descriptive terms such as "sustainable" and "low-carbon footprint," and the questionable validity of some green claims only add to consumer skepticism. This situation reinforces the need for some type of uniformity in claims and for a clear representation of the environmental impact of products

In this article we investigated the consumer effects of text descriptions of the environmental impact of specific product ingredients. The results demonstrate that clearly presented information can make a significant difference in consumer evaluation of products. More specifically, the study found that if green products highlighted the reasons why products with harmful ingredients removed had no negative impact on the environment, and if non-green products were required to disclose the harmful impact of the ingredients they contain, green products would be favorably perceived over the nongreen alternative. Because this type of disclosure is not currently required in the marketplace, we have, at best, a condition where green products provide symbols or in some instances do provide the very positive or positive condition and the non-green product does not provide any information. This is essentially equal to the neutral condition tested in the study. Results of this contrast (positive vs. neutral) indicated no significant differences, and thus the green product did not benefit from its positioning. Full disclosure takes on added importance, given results showing that negative messages have a greater impact than positive messages.

Our findings suggest that policy makers should explore the possibility of requiring manufacturers to disclose key product ingredients and their environmental impact. Drichoutis et al. (2006) found that nutritional label use contributes to a better dietary intake, or to reduced consumption of unhealthy foods. Specifically, they found a positive effect on the consumption of beneficial nutrient components and a negative effect on the consumption of harmful components such as fat and cholesterol. Our results suggest that the same response may result from environmental labeling.

Recently, SC Johnson has taken a step in this direction, by not only listing all product ingredients, but also providing explanations of the purpose of each ingredient. Clearly, we believe a further enhancement that would improve consumer decision-making is providing environmental impact descriptions. Although one might conjecture that despite these findings companies would never list the harmful effects of their products, a decade ago the same argument might have been made about the nutritional content of food products that because many of the ingredients were clearly unhealthy, nutrition information would never be required on package labels. Both the Energy Guide System and the EU Energy Label System are examples of information provided by manufacturers that communicates negative information about 
Table V Comparison of message effects across product categories

\begin{tabular}{|c|c|c|c|c|c|c|c|c|c|c|c|c|}
\hline & \multicolumn{3}{|c|}{ Apple } & \multicolumn{3}{|c|}{ Bar soap } & \multicolumn{3}{|c|}{ MP3 headphones } & \multicolumn{3}{|c|}{ Paper } \\
\hline & $P^{a}{ }^{a}$ & Value & PI & $P Q$ & Value & PI & $P Q$ & Value & PI & $P Q$ & Value & PI \\
\hline Positive $^{\text {b }}$ & 5.33 & 5.15 & 5.25 & 4.44 & 4.79 & 4.51 & 4.15 & 4.04 & 3.52 & 4.48 & 4.69 & 4.70 \\
\hline Negative $^{c}$ & 3.45 & 3.24 & 3.29 & 2.74 & 2.60 & 2.10 & 3.83 & 3.77 & 3.10 & 4.56 & 3.93 & 3.57 \\
\hline Difference & 1.88 & 1.91 & 1.96 & 1.70 & 2.19 & 2.41 & 0.32 & 0.27 & 0.42 & -0.08 & 0.76 & 1.43 \\
\hline
\end{tabular}

Notes: ${ }^{a} 1-7$ Scale; ${ }^{b}$ Very positive and positive scores were averaged; ${ }^{c}$ Very negative and negative scores were averaged

their products. Some have advocated an environmental label similar to the nutritional labeling requirements (Michels, 2008). Mandatory labeling has led to product innovation and product reformulation, and has changed consumer behavior (Drichoutis et al., 2006).

A key decision is the level of environmental impact detail to provide. Although not necessarily focused on a specific ingredient, many companies are exploring the potential for providing additional information details, using data such as the carbon or water footprint, miles traveled, energy used, waste produced, greenhouse gases emitted, and lifecycle effects. Wal-Mart recently announced that they will develop a rating system that will provide the full environmental costs of products to consumers (Bustillo, 2009). The consumer effects of these different metrics are useful avenues for future research. Our results find that there were no significant differences based on the level of detail within a positive or negative category, so the level of detail contained within some of these metrics may be unnecessary.

Currently, organizations are working to develop guidelines for companies that would like to communicate the greenness of their products. Business for Social Responsibility (2008) prepared a report entitled "Eco-promising: communicating the environmental credentials of your products and services". The report suggests that, in order to build trust and to be transparent regarding how and what a company communicates with its customers, a company should:

- seek independent verification of key claims to increase consumer confidence;

- develop a sustainability strategy to ensure that product claims are part of a credible corporate approach;

- adopt a multi-layered approach to getting the message to all customers - using a range of communication channels to satisfy the needs of the most eco-conscious consumer, without overwhelming the less committed;

- anticipate and exploit ground-breaking technologies such as the ability to give consumers environmental information through embedded electronic tags; and

- play an active part in shaping the rules that govern how each industry sector improves and communicates the environmental performance of its products.

Future studies should also examine the number and types of ingredients that should be disclosed. For instance, should only environmental-impacting ingredients that are a significant portion of the product composition be presented, or should the ingredients that have a significant impact on the environment be the ones selected? Our results show that this decision may be category-specific and, particularly for products that produce a direct health impact, it may be more important to disclose the ingredients that impact health regardless of the composition level.

Banning harmful products is not a viable option. When given the choice between banning harmful products and providing additional information, economists argue in support of information. Research has consistently shown that full information leads to better decision making and greater innovation. We hope that future research continues to expand upon the appropriate formats to communicate the ecological impacts of the products consumers purchase and consume.

\section{References}

Abbott, R. (1997), "Food and nutrition information: a study of sources, uses, and understanding", British Food fournal, Vol. 99 No. 2, pp. 43-9.

AlkalizeForHealth (n.d.), "Toxic cosmetics ingredients list", available at www.alkalizeforhealth.net/Ltoxiccosmetics. htm\#28 (accessed October 10, 2008).

Balasubramanian, S.K. and Cole, C. (2002), "Consumers' search and use of nutrition information: the challenge and promise of the Nutrition Labeling and Education Act", Fournal of Marketing, Vol. 66, July, pp. 112-27.

Beach, L.R., Puto, C.P., Heckler, S.E., Naylor, G. and Marble, T.A. (1996), "Differential versus unit weighting of violations, framing, and the role of probability in image theory's compatibility test", Organizational Behavior and Human Decision Making Processes, Vol. 65 No. 2, pp. 77-82.

Bhaskaran, S., Polonsky, M., Cary, J. and Fernandez, S. (2006), "Environmentally sustainable food production and marketing: opportunity or hype?", British Food fournal, Vol. 108 No. 8, pp. 677-90.

Bounds, G. (2009), "As eco-seals proliferate, so do doubts", Wall Street Fournal, April 2, p. D1.

Buda, R. and Zhang, Y. (2000), "Consumer product evaluation: the interactive effect of message framing, presentation order, and source credibility", fournal of Product E Brand Management, Vol. 9 No. 4, pp. 229-42.

Business for Social Responsibility (2008), "Eco-promising: communicating the environmental credentials of your products and services", available at: www.bsr.org/reports/ BSR_Eco-Promising_April_2008.pdf (accessed April 10, 2009).

Bustillo, M. (2009), "Wal-Mart to assign new 'green' ratings", Wall Street Fournal, July 17, p. A4.

California Green Solutions (2007), "Green consumer research outlines the challenge", available at: www. californiagreensolutions.com/cgi-bin/gt/tpl.h,content $=688$ (accessed December 12, 2007).

CBS News (2008), “A closer look at 'green' products manufacturers are making more environmentally friendly products, but not all stand up to the test", May 18, available at: www.cbsnews.com/stories/2008/05/18/ eveningnews/main4105507.shtml (accessed March 24, 2009). 
Conservatree (n.d.), "Trees into paper", available at: www. conservatree.com/learn/EnviroIssues/TreeStats.shtml (accessed October 10, 2008).

Drichoutis, A.C., Lazaridis, P. and Nayga, R.M. Jr (2006), "Consumers' use of nutritional labels: a review of research studies and issues", Academy of Marketing Science Review, No. 9, pp. 1-26.

D'Souza, C., Taghian, M. and Khosla, R. (2007), "Examination of environmental beliefs and its impact on the influence of price, quality and demographic characteristics with respect to green purchase intention", Fournal of Targeting, Measurement and Analysis for Marketing, Vol. 15 No. 2, pp. 69-78.

Environmental Protection Agency (2000), "Addition of diisononyl phthalate category; community right-to-know toxic chemical release reporting", Federal Register, Vol. 65 No. 172, September 5, available at: www.epa.gov/EPA-TRI/ 2000/September/Day-05/tri22656.htm (accessed October 10, 2008).

Esty, D.C. and Winston, A.S. (2006), Green to Gold. How Smart Companies Use Environmental Strategy to Innovate, Create Value, and Build Competitive Advantage, Yale University Press, New Haven, CT and London.

Golan, E. (2000), "Biotech food labeling 2000", Economics of Food Labeling, AER 793, US Department of Agriculture, Washington, DC, pp. 33-7.

Grankvist, G. and Biel, A. (2006), "The impact of environmental information on professional purchasers' choice of products", Business Strategy and the Environment, Vol. 16 No. 6, pp. 421-9.

Grankvist, G., Dahlstrand, U. and Biel, A. (2004), "The impact of environmental labeling on consumer preferences: negative vs positive labels", fournal of Consumer Policy, Vol. 27 No. 2, pp. 213-30.

Green Biz Staff (2009), "Most green labels fail to catch shoppers' eyes, survey finds”, available at: www.greenbiz.co $\mathrm{m} /$ news/2009/09/23/most-green-labels-missing-mark-sur vey-finds (accessed September 23, 2009).

Hartmann Group (2007), The Hartman Report on Sustainability: Understanding the Consumer Perspective, Hartmann Group, Bellevue, WA.

Hawkes, C. (2004), Nutrition Labels and Health Claims: The Global Regulatory Environment, World Health Organization, Geneva.

Heimbach, J.T. and Stokes, R.C. (1982), "Nutrition labeling and public health: survey of American Institute of Nutrition members, food industry, and consumers", The American Fournal of Clinical Nutrition, Vol. 36, October, pp. 700-8.

Jacoby, J., Speller, D.E. and Kohn, C.A. (1974), "Brand choice behavior as a function of information load", fournal of Marketing Research, Vol. 11, February, pp. 63-9.

Johnson, R.D. (1987), "Making judgments when information is missing: inferences, biases, and framing effects", Acta Psychologica, Vol. 66, October, pp. 69-82.

Kahneman, D. and Tversky, A. (1979), "Prospect theory: an analysis of decision under risk", Econometrica, Vol. 47 No. 2, pp. 263-91.

Kaplowitz, J., Hadlock, T. and Levine, R. (2004), "A comparison of web and mail survey response rates", Public Opinion Quarterly, Vol. 68, pp. 94-101.

Laroche, M., Bergeron, J. and Barbaro-Forleo, G. (2001), "Targeting consumers who are willing to pay more for environmentally friendly products", The fournal of Consumer Marketing, Vol. 18 No. 6, pp. 503-20.
Levin, I.P. and Gaeth, G.J. (1988), "Framing of attribute information before and after consuming the product", The Fournal of Consumer Research, Vol. 15, December, pp. 374-8. Levin, I.P., Schneider, S. and Gaeth, G.J. (1998), "All frames are not created equal: a typology and critical analysis of framing effects", Organizational Behavior and Human Decision Processes, Vol. 76 No. 2, pp. 149-88.

Mazur, A. (2010), "State of green business forum", February 9, available at: www.worldchanging.com/ archives/010971.html (accessed February 15, 2010).

Michels, S. (2008), "Environmental demand drives ecofriendly products", available at: www.pbs.org/newshour/bb/ environment/july-dec08/greengoods_08-15.html (accessed August 15, 2008).

Pickett-Baker, J. and Ozaki, R. (2008), "Pro-environmental products: marketing influence on consumer purchase decision", fournal of Consumer Marketing, Vol. 25 No. 5, pp. 281-93.

Rotherham, T. (1999), "Meeting of Technical Specialists and Policy Experts on Environmentally-Sound Trade Expansion in the Americas. Selling Sustainable Development: Environmental Labeling and Certification Programs, University of Miami, October 28-29", available at: www.iisd.org/standards/pdf/miami_paper_final.pdf (accessed March 25, 2009).

Smith, S.M. and Petty, R.E. (1996), "Message framing and persuasion: a message process analysis”, Personality and Social Psychology Bulletin, Vol. 22 No. 3, pp. 257-88.

Terrachoice Environmental Marketing (2009), The Seven Sins of Greenwashing, Terrachoice Environmental Marketing, Ottawa, April.

Thøgersen, J. (2000), "Psychological determinants of paying attention to eco-labels in purchase decisions: model development and multinational validation", fournal of Consumer Policy, Vol. 23 No. 3, pp. 285-315.

Tversky, A. and Kahneman, D. (1981), "The framing of decisions and the psychology of choice", Science, Vol. 211 No. 4481, pp. 453-8.

US Environmental Protection Agency (n.d.), "What is a pesticide?", available at: epa.gov/opp00001/about/ (accessed October 10, 2008).

Veisten, K. (2007), "Willingness to pay for eco-labelled wood furniture: choice-based conjoint analysis versus open-ended contingent valuation", fournal of Forest Economics, Vol. 13 No. 1, pp. 29-48.

Vlosky, R.P., Ozanne, L.K. and Fontenot, R.J. (1999), "A conceptual model of US consumer willingness-to-pay for environmentally certified wood products", The fournal of Consumer Marketing, Vol. 16 No. 2, pp. 122-40.

Vurtur.com Eco-friendly Services (n.d.), "Eco-friendly solutions", available at: www.vurtur.com/en/print-services/ eco-friendly-solutions (accessed October 10, 2008).

Wasserman, T. (2009), “Mintel: 'green' products top 5,933 in 2007", May 20, available at: www.brandweek.com/bw/ news/packaged/article_display.jsp?vnu_content_id= 1003805821 (accessed March 24, 2009).

Weigel, R. and Weigel, J. (1978), "Environmental concern: the development of a measure", Environment and Behavior, Vol. 10 No. 1, pp. 3-15.

Witte, K. (1992), "Putting the fear back into fear appeals: the extended parallel process model", Communications Monographs, Vol. 59, December, pp. 329-49.

Wüstenhagen, R. (1998), "Pricing strategies on the way to ecological mass markets", Greening of Industry Network Conference, pp. 1-24. 


\section{Appendix}

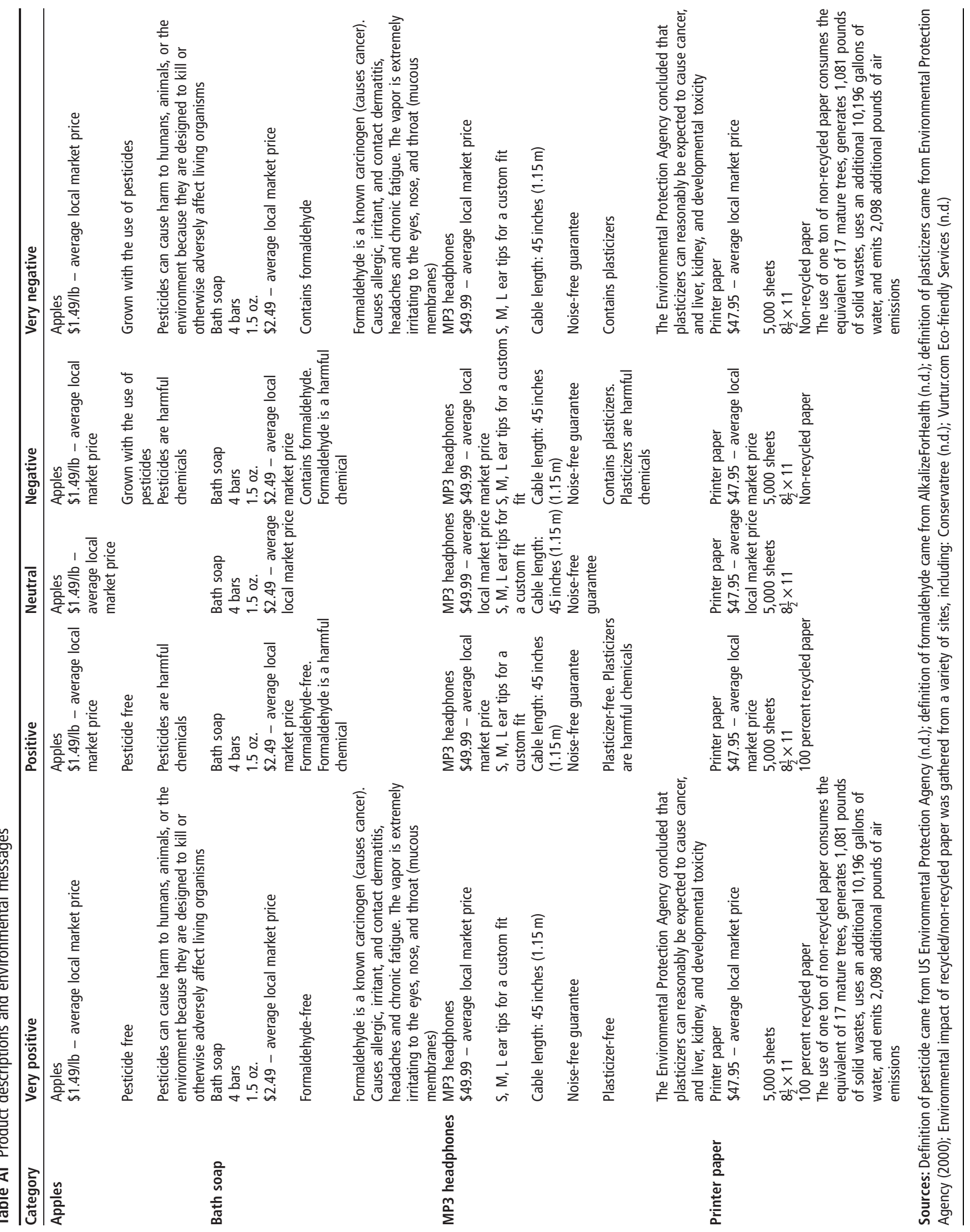




\section{About the authors}

Norm Borin is a Professor of Marketing at the Orfalea College of Business California Polytechnic State University. His current research includes an investigation of strategies in marketing sustainability and the development of pedagogical learning tools for marketing courses. His work has appeared in a variety of journals, including the fournal of Retailing, Decision Sciences, Fournal of Marketing Education, Fournal of Direct Marketing, Fournal of the Academy of Business, Fournal of Interactive Marketing. Norm Borin is the corresponding author and can be contacted at: nborin@calpoly.edu

Douglas C. Cerf is the KPMG Faculty Fellow in Accounting. $\mathrm{He}$ is an Accounting Professor and the Area Chair of the accounting area. Prior to this appointment, he served as the associate dean of the Orfalea College of Business for six years and was responsible for undergraduate programs. He teaches intermediate and advanced financial reporting courses. He has been a visiting professor at the following universities: Bren Graduate School of Environmental Science and Management at the University of California at Santa Barbara; Copenhagen Business School, and Politecnico di Milano. His recent research focuses on accounting and financial management to support sustainability, accounting guidance that impacts the public interest, as well as information disclosure on environmental labeling. His articles have also appeared in the following journals: Issues in Accounting Education, American Institute of Certified Public Accountants Professor Practitioner Case Program, Fournal of the Academy of Business Education, Fournal of Marketing Education, Management Accounting and Managerial Finance.

R. Krishnan (PhD Virginia Tech) is the Research Professor of Marketing, University of Miami and Professor Emeritus, Cal Poly SLO. He was previously Director of Graduate Programs and Professor of Marketing at Cal Poly, San Luis Obispo. His research has appeared in a number of professional and scholarly journals, including the fournal of Marketing, Fournal of Interactive Marketing, Sloan Management Review, California Management Review, The Academy of Management Executive, Total Quality Management, Fournal of Retailing, Fournal of Advertising, Fournal of Advertising Research, The fournal of Business Logistics, European fournal of Marketing, Industrial Marketing Management, Fournal of Business Research, Fournal of Consumer Psychology, Industrial Marketing Management, Fournal of Marketing Management, and The International Fournal of Physical Distribution.

\section{Executive summary and implications for managers and executive readers}

This summary has been provided to allow managers and executives a rapid appreciation of the content of the article. Those with a particular interest in the topic covered may then read the article in toto to take advantage of the more comprehensive description of the research undertaken and its results to get the full benefit of the material present.

A growing number of consumers are purchasing eco-friendly products and many have demonstrated their willingness to pay higher prices for such goods. Reports have shown that concern about the environment is rising and that people are engaging in activities that help to protect it. This prevailing mood has led to an increase in the development and launch of green products, the amount of which more than doubled in the US market between 2005 and 2007.
Studies have, however, identified factors that disturb many consumers and might threaten growth and sustainability of the market. For instance, there is the issue of product value. When compared with non-green alternatives, the belief among many consumers is that green products are excessively priced and of suspect quality.

Plenty evidence suggests that even greater concern surrounds communication. Such is the perceived lack of information and clarity on product labels that a significant majority of consumers struggle to distinguish products that are more environmentally friendly than others. People are aware of the various labels introduced by governments, other bodies and even corporations themselves but swamping the market with this array of often conflicting symbols only adds to the confusion experienced. It does not help that even the most recognized symbols used can convey more than one meaning. Some scholars note that labels thus function to challenge rather than inform the consumer.

As a result, demands to improve communication are gathering momentum. Those clamoring for change point out the need for information that is readily accessible and easy to comprehend. Making relevant information available at the point of purchase can further help to educate consumers about the benefits of choosing a greener lifestyle.

Accuracy of communication is equally important. Research has shown that companies that provide misleading or imprecise environmental claims can have a detrimental effect on how consumers perceive the industry in general. Sometimes the information will be relevant, yet incomplete. An example of this is labels that reveal energy consumption levels of washing machines, but do not refer to water usage despite it being equally pertinent.

The difficulty here is compounded by the fact that manufacturers do not currently have to list all product ingredients. Consequently, people often remain unaware of the likely environmental impact of certain products. That disclosure of ingredients is also optional for non-green products increases the difficulty faced by consumers hoping to make an informed choice. Certain companies do provide extensive product information but they are in the minority. It is the opinion of Borin et al. that such openness about both positive and negative environmental impact must become the norm in order to persuade more consumers to buy ecofriendly products.

At present, considerable inconsistency surrounds the quality of environmental information included on product labels. At one end of the spectrum are basic symbols or other minimal detail, while exhaustive descriptions of product ingredients and their significance might be found at the other. It is a core assumption of the present study that information can significantly influence consumer perceptions of the product and their purchase intention.

Previous research has found that:

- Consumer response is more favorable towards positive messages about attributes than when it is negative. Evaluations can be subsequently transferred to the product or object.

- Negative information on a product label can have a greater effect than positive information on consumers who have an "intermediate interest" in the environment. The premise here is that such customers are more concerned about things getting worse than making improvements. Another explanation offered is that people typically indicate greater sensitivity to losses than gains. 
- Quality rather than quantity of information is important as too much information inhibits decision-making capabilities. Whether people actually prefer more or less is, however, unclear.

- The impact of negative product information is more profound when it directly concerns consumer health.

The authors investigate key issues in an experimental study involving 329 university students. A survey was used and participants were presented with one of four scenarios concerning different products believed to pose varying levels of threat to consumer health due to their ingredients or materials used. Product labels were also included in each scenario and carried one of five types of environmental information ranging from very positive to very negative, with a neural position in the middle. Subjects were asked to consider themselves as potential buyers and indicate the perceived quality, value and purchase intention with regard to the products. A key aim of the study was to measure whether results vary by product category and environment-related message.

Most respondents had recently purchased the products, showed varying degrees of familiarity with the ingredients or processes and demonstrated some affinity with environmental attitudes and behaviors. The findings suggested that environmental product information will have greater:

- positive influence on the consumer when it is positive rather than negative;

- negative impact on consumer metrics when the information is negative rather than neutral; and

- overall impact on the consumer when it is negative rather than positive.

It was indicated that varying the level of detail included about product ingredients did not produce differing effects. Some support for the proposal that environmental information would have most impact for products that contain ingredients potentially detrimental to both the environment and consumer health was also evident. Based on the literature Borin et al. anticipated that any differences in the impact on consumer metrics between the positive and neutral or no information conditions would not be significant. In this respect, results were inconclusive.

The authors argue that this study strengthens the argument that a uniform approach is needed with regard to environmental product information. They point out the considerable difference on consumer evaluation when relevant details are clearly conveyed. And given the greater impact of negative information, it is also suggested that forcing companies to disclose the potentially damaging effects of ingredients used could feasibly lead to more consumers choosing greener options. The food industry is cited as an example where providing important nutritional information has enabled consumers to improve their diets.

That some companies are developing initiatives of their own is noted. A key report outlines that organizations could take measures such as:

- obtain independent verifications of claims made;

- develop a sustainability strategy;

- use relevant communication channels to reach environmentally-conscious consumers and those less dedicated;

- exploit new technologies as a means of conveying information to the consumer; and

- become actively involved in creating an industry framework for ensuring that firms improve their communication and ecological performance.

Future studies might consider how much environmental information a company needs to disclose about its product. For instance, whether or not the consumer needs informing about every ingredient is one issue to explore. Since the study suggested that some details might be unnecessary, research might be able to determine what constitutes an optimal level. 